\begin{tabular}{|c|c|}
\hline Title & $\begin{array}{l}\text { Effect of pal onosetron and dexamethasone administration on the prevention of gastrointestinal symptoms in hepatic } \\
\text { arterial chemoembolization with epirubicin }\end{array}$ \\
\hline Author(s) & $\begin{array}{l}\text { Sakamoto, Tatsuhiko; Saito, Y oshitaka; Kobay ashi, Masaki; Y amada, Takehiro; Takekuma, Y oh; Nakai, Masato; } \\
\text { Ogawa, Koji; Iseki, Ken; Sugawara, Mitsuru }\end{array}$ \\
\hline Citation & $\begin{array}{l}\text { Supportive care in cancer, 28(7), 3251-3257 } \\
\text { https://doi.org/10.1007/s00520-019-05178-1 }\end{array}$ \\
\hline Issue Date & $2020-07$ \\
\hline Doc URL & http:/hdl.handle.net/2115/82352 \\
\hline Rights & $\begin{array}{l}\text { This is a post-peer-review, pre copy edit version of an article published in Supportive Care in Cancer. The final } \\
\text { authenticated version is available online at: } h \text { http://dx.doi.org/10.1007//00520-019-05178-1 }\end{array}$ \\
\hline Type & article (author version) \\
\hline File Information & WoS_94484_Sakamoto.pdf \\
\hline
\end{tabular}

Instructions for use 
Title

\section{Effect of palonosetron and dexamethasone administration on the prevention of gastrointestinal symptoms in hepatic} arterial chemoembolization with epirubicin

Tatsuhiko Sakamoto $^{1}$, Yoshitaka Saito ${ }^{1}$, Masaki Kobayashi ${ }^{2}$, Takehiro Yamada ${ }^{4}$, Yoh Takekuma ${ }^{1,3}$, Masato Nakai ${ }^{5}$, Koji Ogawa $^{5}$ Ken Iseki ${ }^{2}$ Mitsuru Sugawara*1,3

${ }^{1}$ Department of Pharmacy, Hokkaido University Hospital: Kita 14-jo, Nishi 5-chome, Kita-ku, Sapporo 060-8648, Japan

${ }^{2}$ Laboratory of Clinical Pharmaceutics \& Therapeutics, Faculty of Pharmaceutical Sciences, Hokkaido University: Kita 12-jo, Nishi 6-chome, Kita-ku, Sapporo 060-0812, Japan

${ }^{3}$ Laboratory of Pharmacokinetics, Faculty of Pharmaceutical Sciences, Hokkaido University: Kita 12-jo, Nishi 6-chome, Kita-ku, Sapporo 060-0812, Japan

${ }^{4}$ Department of Pharmacy, Hokkaido University of Science: 7-jo, 14-4-1 Maeda, Teine, Sapporo 006-8585, Japan

${ }^{5}$ Department of Gastroenterology and Hepatology, Hokkaido University Graduate School of Medicine: Kita 15-jo, Nishi 7-chome, Kita-ku, Sapporo 060-8638, Japan

*To whom correspondence should be addressed.

Mitsuru Sugawara, Ph. D.,

Department of Pharmacy, Hokkaido University Hospital

Kita 14-jo, Nishi 5-chome, Kita-ku, Sapporo 060-8648, Japan

Tel: $+81-11-706-5680$

Fax: +81-11-706-7616

E-mail:msuga@pharm.hokudai.ac.jp 


\begin{abstract}
Purpose

There are several studies on premedication to prevent postembolization syndromes which occurs after transcatheter arterial chemoembolization (TACE), but the medication to be used is still not established. This study aimed to examine the effect of palonosetron and dexamethasone on the prevention of gastrointestinal symptoms induced by TACE.
\end{abstract}

\title{
Methods
}

Patients with hepatocellular carcinoma who were treated with TACE with epirubicin were retrospectively evaluated.

The complete response rate of antiemetic drugs and incidence and severity of gastrointestinal symptoms were compared between the antiemetic group (AE group), which includes 51 patients prophylactically administered with palonosetron $0.75 \mathrm{mg}$ and dexamethasone $9.9 \mathrm{mg}$ intravenously before TACE on day 1 and dexamethasone $6.6 \mathrm{mg}$ intravenously on days 2 and 3, and control group with 101 patients without antiemetic premedication.

\section{Results}

Complete response rate in the entire evaluation period was significantly higher in the AE group compared to that in the control group. In the acute phase, the incidence and severity of nausea, vomiting, and anorexia significantly decreased in the AE group, but only anorexia improved in the delay phase. Additionally, postembolization syndromes, such as abdominal pain and fever, were significantly attenuated in the AE group; however, constipation worsened in this group.

\section{Conclusions}

Premedication of palonosetron and dexamethasone significantly prevents the incidence and reduces the severity of gastrointestinal symptoms especially in the acute phase. Further studies will be needed to determine the most recommended 5- $\mathrm{HT}_{3}$ antagonist or dosage of dexamethasone in establishing the optimal antiemetic regimen. 
Keywords: Transcatheter arterial chemoembolization (TACE); epirubicin; postembolization syndromes; nausea; 5-HT 3 antagonist; dexamethasone 


\section{Introduction}

The number of annual deaths due to liver cancer is slowly decreasing in Japan. However, the number of patients

surpasses 30,000, and many patients still need treatment. The causes of liver cancer include hepatitis $\mathrm{C}$ virus and/or hepatitis B virus infection, drinking habit, and nonalcoholic steatohepatitis. The treatment strategy for hepatocellular carcinoma (HCC) is selected according to the liver function, number of tumors, and tumor diameter. Even in liver resection, which is the most excellent in local control, the recurrence rate is as high as $51.6-70.3 \%$ in 2 years postoperatively [1-2]. Transcatheter arterial chemoembolization (TACE) is one of the topical therapies in advanced HCC and contributes to the improvement of its prognosis [3-4]. The recurrence rate of HCC in 5 years after topical therapy is 70-80\%; therefore, TACE is repeatedly performed at the time of recurrence [5-6]. There are several anticancer drugs administered in TACE. Epirubicin (EPI), which is categorized as an anthracycline-type drug, is one of the most frequently used cytotoxic agents and administered as emulsion with an oil contrast medium in TACE. Postembolization syndromes, known to be the adverse effects of TACE, include symptoms such as nausea, vomiting, anorexia, fever, and abdominal pain and often develop within 1-2 weeks from the embolization day [7]. Although their mechanism has not been fully elucidated, it is considered that systemic effects caused by anticancer drugs and inflammation caused by inflammatory mediators released from ischemia and necrotic cells are involved [8]. Nausea is the most common and one of the most painful adverse events in systemic chemotherapy. The incidence of nausea in TACE with EPI is approximately $30-50 \%$ [9-10]. In systemic chemotherapy, guidelines for the administration of antiemetic drugs are instituted, and prophylactic administration of antiemetic drugs, such as $\mathrm{NK}_{1}$ receptor antagonists, 5- $\mathrm{HT}_{3}$ receptor antagonists, and dexamethasone, are necessary according to the risk classification of nausea for each anticancer drug.

Although several studies revealed that prophylactic administration of antiemetic drugs, such as 5-HT $\mathrm{H}_{3}$ receptor antagonists, dexamethasone, and scopolamine or their combination, is effective in the prevention of TACE-induced 
nausea, there are no definite views on the most recommended antiemetic regimen. It has been reported that prophylactic administration of dexamethasone is effective in preventing TACE-induced nausea [7, 11]. In contrast, other studies suggest that dexamethasone should not be routinely administered considering its adverse effects [12]. Even though the duration of postembolization syndromes is short, its management is important to maintain the patient's quality of life since TACE is repeatedly performed. As EPI use is classified as having a moderate emetic risk (MEC) in antiemetic guidelines for systemic chemotherapy [13], we have assumed that EPI use in TACE has a moderate nausea risk. In this study, we have examined whether prophylactic administration of 5- $\mathrm{HT}_{3}$ receptor antagonist and dexamethasone is effective in preventing TACE-induced nausea.

\section{Patients and Methods}

1. Patients

Patients with HCC who were treated with TACE with EPI for the first time were retrospectively evaluated. Patients were divided into two groups: antiemetic group (AE group), which includes 51 patients prophylactically administered with antiemetic drugs before TACE from October 2015 to December 2016, and control group with 101 patients without antiemetic premedication from August 2008 to October 2015. This retrospective study was approved by the Institutional Review Board of the Hokkaido University Hospital (017-0060) and conducted in accordance with the Declaration of

Helsinki.

2. Treatment methods

TACE using lipiodol (Guerbet, Roissy CdG, France) with gelatin sponge particles (Gelpart; Nippon Kayaku, Tokyo, Japan) was performed for each patient. EPI plus lipiodol emulsion was prepared by mixing $5 \mathrm{~mL}$ of lipiodol and $50 \mathrm{mg}$ of EPI (Nippon Kayaku, Tokyo, Japan) dissolved in $5 \mathrm{~mL}$ of contrast medium. Total lipiodol volume was calculated 
according to the total HCC volume: for an HCC nodule with a diameter of $1 \mathrm{~cm}$, approximately $1 \mathrm{~mL}$ of lipiodol was used. To avoid liver damage, the maximum lipiodol dose was limited to $10 \mathrm{~mL}$. Patients in the AE group were treated with palonosetron $0.75 \mathrm{mg}$ and dexamethasone $9.9 \mathrm{mg}$ intravenously before TACE on day 1 and dexamethasone $6.6 \mathrm{mg}$ intravenously on days 2 and 3. No antiemetic drugs were prophylactically administered in the control group. Antiemetic drugs, such as metoclopramide or chlorpromazine, were administered as rescue medications according to the physician's decision.

\section{Evaluation criteria}

In the evaluation period, day 1 was defined as the acute phase and days $2-6$ as the delay phase at the first

implementation of TACE. The primary endpoint was complete response (CR), which was defined as the absence of vomiting and absence of additional treatment with antiemetic drugs in the entire evaluation period. We have also evaluated the incidence and severity of nausea, vomiting, and anorexia and incidence of constipation and headache as adverse effects caused by antiemetic drugs. Moreover, we also investigated whether this premedication affects the development of postembolization syndromes, such as fever and abdominal pain. For the evaluation criteria, we used Common Terminology Criteria for Adverse Events version 4. Patients who have already been administered with antiemetic drugs, such as dopamine 2 receptor antagonist or histamine 1 receptor antagonist, at baseline, those with nausea before TACE, and those who were administered with drugs causing nausea, such as narcotics, were excluded.

\section{Statistical analysis}

We hypothesized that the $\mathrm{CR}$ rate would reach $70 \%$ in the control group and $90 \%$ in the $\mathrm{AE}$ group. We have set the patient ratio to 2:1 between the control and $\mathrm{AE}$ groups. A sample size of 101 in the control group and 51 in the $\mathrm{AE}$ group was required to achieve $80 \%$ power with an alpha error of $5 \%$.

The differences in baseline clinical characteristics between the AE and control groups were assessed using Fisher's 
exact probability test for categorical outcome variables and Mann-Whitney U test for continuous parameters. Differences in CR rate and incidence of gastrointestinal symptoms, postembolization syndromes, and adverse events between the two groups were analyzed using Fisher's exact probability test. Differences in the degree of severity of gastrointestinal symptoms between the two groups were assessed using the Mann-Whitney U test. Differences were considered to be statistically significant when the $P$-value was $<0.05$.

\section{Results}

\section{Patient's background}

Patient characteristics are shown in Table 1. There was no significant difference between the control and AE groups with respect to sex, age, performance status, body surface area, and drinking history. EPI dosage was also similar in both groups. Liver dysfunction and renal dysfunction were not different in both groups. Only TNM classification had a significant difference between the two groups.

2. Comparison of $\mathrm{CR}$ rate and incidence of gastrointestinal symptoms

Table 2 shows that the CR rate in the entire evaluation period was significantly higher in the AE group compared to that in the control group. This result suggests that prophylaxis with palonosetron and dexamethasone significantly decreased the incidence of gastrointestinal symptoms caused by TACE with EPI and additional administration of antiemetic drugs. In the acute phase, the incidence of nausea, vomiting, and anorexia significantly decreased in the AE group, suggesting that prophylactic administration of palonosetron and dexamethasone is effective in preventing acute gastrointestinal symptoms caused by TACE with EPI. In contrast, prophylactic administration of antiemetic drugs did not affect the incidence of nausea and vomiting in the delay phase although the incidence of anorexia significantly decreased. 
Prophylactic administration of antiemetic drugs significantly ameliorated the severity of nausea and anorexia in the acute phase, whereas there was no difference in severity of gastrointestinal symptoms in the delay phase (Table 3).

4. Comparison of postembolization syndromes and adverse effects of antiemetic drugs

Table 4 shows the incidence of fever and abdominal pain, which are representative symptoms of postembolization syndromes and adverse effects caused by antiemetic drugs. It was shown that it was significantly reduced by premedication in the entire evaluation period. Constipation, which is a typical adverse effect of palonosetron, was significantly worsened by administration of premedication. As for headaches, changes due to antiemetic administration were not observed.

\section{Discussion}

TACE is important in the treatment of unresectable HCC; however, $47.7 \%$ of patients develop postembolization syndromes after TACE [14]. Postembolization syndromes are symptoms such as nausea, vomiting, anorexia, fever, and abdominal pain and develop within 1-2 weeks from the embolization day [7]. Since TACE is repeatedly performed, management of postembolization syndromes is also important to maintain the patient's quality of life and advance to smooth treatment of HCC. There are several studies on premedication to prevent postembolization syndromes $[7,9,11-$ 12], but the medication to be used and the best dosage are still not established. In this study, we have examined the effect of palonosetron and dexamethasone on the prevention of gastrointestinal symptoms in TACE.

It was suggested that prophylactic administration of palonosetron and dexamethasone is efficacious in patients who underwent TACE with EPI, since a significant increase in CR rate and reduction in the incidence and severity of gastrointestinal symptoms were observed in the $\mathrm{AE}$ group. $5-\mathrm{HT}_{3}$ receptor antagonists and dexamethasone have been reported to prevent nausea, vomiting, and anorexia associated with TACE $[9,11,15-16]$. The results in this study are 
consistent with those of other studies. It is known that 5- $\mathrm{HT}_{3}$ receptors in the gastrointestinal tract and chemoreceptor trigger zone are stimulated by anticancer agents, resulting in nausea induction. Although the mechanism of TACEinduced nausea is not sufficiently elucidated, it might be similar to that of chemotherapy-induced nausea; therefore, it could be possible to speculate that palonosetron could decrease the incidence of TACE-induced nausea. Palonosetron has higher 5- $\mathrm{HT}_{3}$ receptor binding affinity (at least 30-fold higher) and longer plasma elimination half-life (approximately 40 h) compared with older antagonists [17]. Due to these features, palonosetron is superior to the first-generation $5-\mathrm{HT}_{3}$ receptor antagonists in antiemetic effect in the delay phase [18]. However, in this present study, the incidence and severity of the gastrointestinal symptoms in the acute phase have improved, whereas improvement in the delay phase has been achieved only in anorexia. In the control group, while the CR rate in the acute phase is 59\%, the CR rate in the delay phase is $77 \%$, suggesting that gastrointestinal symptoms induced by TACE with EPI are likely to occur in the acute phase. In a previous study, $35.6 \%$ of patients developed nausea on day 1 , and the number decreased to approximately half on day 2 [9]. Nausea and vomiting in the delay phase are considered mild even in the control group; therefore, there was no significant difference between the two groups in improvement of symptoms in this phase.

In this study, dexamethasone was also likely to contribute to amelioration of gastrointestinal symptoms in the acute phase and anorexia in the delay phase. Dexamethasone is considered to improve digestive symptoms by its antiemetic effect on anticancer agents, appetite-promoting effect, and anti-inflammatory effect. Although several studies reported that dexamethasone has reduced the incidence of TACE-induced nausea, the dosage varies in each report [7, 11-12]. Dexamethasone has been administered in multiple days in the studies, and Kogut et al. reported that a single dose of dexamethasone is ineffective in preventing gastrointestinal symptoms [12]. Sadahira et al. also reported that the combination of dexamethasone and granisetron significantly improved gastrointestinal symptoms in the acute and delay phased compared to granisetron alone [11]. In their study, they used miriplatin as the anticancer agent for TACE. 
Previous studies have shown that EPI and miriplatin have no difference in the incidence of adverse events after TACE, including nausea and vomiting [19-20]. However, there are few studies that evaluated the acute and delay phases separately. Although the prophylactic administration of antiemetic drugs in the control group in this study and that in Sadahira et al.'s study differs by the presence or absence of granisetron, the respective results show that miriplatin is likely to prolong nausea and vomiting in the delay phase. However, those symptoms induced by TACE with EPI is likely to develop in the acute phase; therefore, it is considered that significant differences in the delay phase would be observed in their study but not in this study. Dexamethasone has been reported to reduce the incidence of postembolization syndromes, such as fever and abdominal pain, other than nausea [7, 11-12, 21-23], and similar results were observed in this study. It is considered that improvement in anorexia in the delay phase in the AE group might be observed by decreasing pain and fever through the anti-inflammatory effect of dexamethasone rather than the antiemetic effect on anticancer agents.

The incidence of nausea induced by TACE in the acute phase reaches approximately $20 \%$ in this study and other studies $[9,11]$ even with prophylactic administration of antiemetic drugs, and this is higher than that in systemic chemotherapy [24]. It is presumed that it was caused by not only anticancer agents but also the stress response due to invasive treatment, abdominal pain in postembolization syndromes, and release of inflammatory substances by tumor destruction. Although surgery is a typical invasive treatment, $5-\mathrm{HT}_{3}$ receptor antagonist is known to be efficacious in postoperative nausea and vomiting [25]. Moreover, it is presumed that dexamethasone reduces pain in postembolization syndromes and the inflammatory reaction caused by tumor destruction. From these facts, it is reasonable to use the combination of $5-\mathrm{HT}_{3}$ receptor antagonist and dexamethasone in the prevention of gastrointestinal symptoms after TACE.

Constipation significantly worsened by administration of antiemetic drugs, mainly caused by palonosetron. Defecation control is important in patients with HCC since they are often complicated with liver cirrhosis. It is important to control 
constipation with laxatives and prevent hepatic encephalopathy. Constipation is caused by $5-\mathrm{HT}_{3}$ antagonists, and palonosetron has a longer effect; thus, first-generation 5- $\mathrm{HT}_{3}$ antagonists may be useful. As evaluation was difficult, the influence of dexamethasone on the blood glucose level was not investigated in this study. The incidence of diabetes mellitus in patients with liver cirrhosis from HCC is reported to exceed 30\% [26], and elevation of blood glucose level by steroids is considered as an undesirable effect as TACE is repeatedly performed. For patients with diabetes mellitus, it could be better to reduce or stop pre-administration of dexamethasone depending on the individual.

There are some limitations in the evaluation of antiemetic effect of prophylactic administration of palonosetron and dexamethasone. First, this was a retrospective study with a relatively small population of patients. Therefore, it is necessary to conduct a large-scale prospective study to confirm these results. Second, in Japan, $0.75 \mathrm{mg}$ of palonosetron is adopted, but $0.25 \mathrm{mg}$ is the standard internationally, so a study using palonosetron $0.25 \mathrm{mg}$ should be conducted. Third, TNM stage had a significant difference between the two groups; therefore, the control group had a larger number of patients with higher severity than the AE group. Adverse events induced by TACE might strongly occur in the control group; hence, a study aligning the patient's background should be conducted. Lastly, we have evaluated only patients who have been treated with TACE for the first time; therefore, we should also evaluate patients who were repeatedly treated with TACE.

Therefore, it was revealed that premedication of palonosetron and dexamethasone according to antiemetic premedication in the MEC regimen significantly decreases the incidence and severity of gastrointestinal symptoms. Additionally, it significantly attenuated postembolization syndromes, such as abdominal pain and fever. Further studies will be needed to determine the most recommended 5- $\mathrm{HT}_{3}$ antagonist or dosage of dexamethasone to establish the optimal antiemetic regimen. 


\section{Compliance with Ethical Standards}

\section{Disclosure of potential conflicts of interest}

Funding: This work was funded by JSPS KAKENHI Grant Number $17 \mathrm{H} 00565$.

Conflict of Interest: All authors declare that they have no conflict of interest.

\section{Research involving Human Participants}

Ethical approval: All procedures performed in studies involving human participants were in accordance with the

ethical standards of the institutional and/or national research committee and with the 1964 Helsinki declaration and its later amendments or comparable ethical standards. For this type of study formal consent is not required. 


\section{References}

1. Liu H, Wang ZG, Fu SY, Li AJ, Pan ZY, Zhou WP et al (2016) Randomized clinical trial of chemoembolization plus radiofrequency ablation versus partial hepatectomy for hepatocellular carcinoma within the Milan criteria. Brit $J$ Surg 103: 348-356.

2. Sakaguchi T, Suzuki S, Morita Y, Oishi K, Suzuki A, Fukumoto K et al (2010) Impact of the preoperative desgamma-carboxy prothrombin level on prognosis after hepatectomy for hepatocellular carcinoma meeting the Milan criteria. Surg Today 40:638-645.

3. Lo CM, Ngan H, Tso WK, Liu CL, Lam CM, Poon RT et al (2002) Randomized controlled trial of transarterial lipiodol chemoembolization for unresectable hepatocellular carcinoma. Hepatology 35:1164-1171.

4. Llovet JM, Real MI, Montaña X, Planas R, Coll S, Aponte J et al (2002) Arterial embolisation or chemoembolisation versus symptomatic treatment in patients with unresectable hepatocellular carcinoma: a randomised controlled trial.

Lancet 359: 1734-1739.

5. Takayasu K1, Muramatsu Y, Maeda T, Iwata R, Furukawa H, Muramatsu Y et al (2001) Targeted transarterial oily chemoembolization for small foci of hepatocellular carcinoma using a unified helical CT and angiography system: analysis of factors affecting local recurrence and survival rates. AJR Am J Roentgenol 176:681-688.

6. Matsui O1, Kadoya M, Yoshikawa J, Gabata T, Arai K, Demachi H et al (1993) Small hepatocellular carcinoma: treatment with subsegmental transcatheter arterial embolization. Radiology 188:79-83.

7. Yinglu F, Changquan L, Xiaofeng Z, Bai L, Dezeng Z, Zhe C (2009) A new way: alleviating postembolization syndrome following transcatheter arterial chemoembolization. J Altern Complement Med 15:175-181. 
8. Fiorentini G, Aliberti C, Tilli M, Mulazzani L, Graziano F, Giordani P (2012) Intra-arterial infusion of irinotecanloaded drug-eluting beads (DEBIRI) versus intravenous therapy (FOLFIRI) for hepatic metastases from colorectal cancer: final results of a phase III study. Anticancer Res 32:1387-1395.

9. Sohara N, Takagi H, Abe T, Hashimoto Y, Kojima A, Takahashi H et al (1997) Nausea and vomiting induced by arterial chemo-embolization in patients with hepatocellular carcinoma and the antiemetic effect of ondansetron hydrochloride. Support Care Cancer 7:84-88.

10. Sahara S, Kawai N, Sato M, Tanaka T, Ikoma A, Nakata K et al (2012) Prospective evaluation of transcatheter arterial chemoembolization (TACE) with multiple anti-cancer drugs (epirubicin, cisplatin, mitomycin c, 5fluorouracil) compared with TACE with epirubicin for treatment of hepatocellular carcinoma. Cardiovasc Intervent Radiol 35:1363-1371.

11. Ogasawara S, Chiba T, Ooka Y, Kanogawa N, Motoyama T, Suzuki E et al (2017) A randomized placebo-controlled trial of prophylactic dexamethasone for transcatheter arterial chemoembolization. Hepatology 67:576-585.

12. Kogut MJ, Chewning RH, Harris WP, Hippe DS, Padia SA (2013) Postembolization syndrome after hepatic transarterial chemoembolization: effect of prophylactic steroids on postprocedure medication requirements. $J$ Vasc Interv Radiol 24:326-331.

13. Hesketh PJ, Kris MG, Basch E, Bohlke K, Barbour SY, Clark-Snow RA et al (2017) Antiemetics: American Society of Clinical Oncology Clinical Practice Guideline Update. J Clin Oncol 35:3240-3261.

14. Lencioni R, de Baere T, Soulen MC, Rilling WS, Geschwind JF (2016) Lipiodol transarterial chemoembolization for hepatocellular carcinoma: a systematic review of efficacy and safety data. Hepatology 64:106-116.

15. Prajapati HJ, Rafi S, El-Rayes BF, Kauh JS, Kooby DA, Kim HS (2012) Safety and feasibility of same-day discharge of patients with unresectable hepatocellular carcinoma treated with doxorubicin drug-eluting bead 
transcatheter chemoembolization. J Vasc Interv Radiol 23:1286-1293.

16. de Baere T, Deschamps F, Teriitheau C, Rao P, Conengrapht K, Schlumberger M et al (2008) Transarterial chemoembolization of liver metastases from well differentiated gastroenteropancreatic endocrine tumors with doxorubicin-eluting beads: preliminary results. J Vasc Interv Radiol 19:855-861.

17. Celio L, Niger M, Ricchini F, Agustoni F (2015) Palonosetron in the prevention of chemotherapy-induced nausea and vomiting: an evidence-based review of safety, efficacy, and place in therapy. Core Evid 10:75-87.

18. Hashimoto H, Yamanaka T, Shimada Y, Arata K, Matsui R, Goto K et al (2013) Palonosetron (PALO) versus granisetron (GRA) in the triplet regimen with dexamethasone (DEX) and aprepitant (APR) for preventing chemotherapy-induced nausea and vomiting (CINV) in patients (pts) receiving highly emetogenic chemotherapy (HEC) with cisplatin (CDDP): a randomized, double-blind, phase III trial. J Clin Oncol 31(Suppl):9621.

19. Ikeda M, Kudo M, Aikata H, Nagamatsu H, Ishii H, Yokosuka O (2018) Transarterial chemoembolization with miriplatin vs. epirubicin for unresectable hepatocellular carcinoma: a phase III randomized trial. J Gastroenterol 53:281-290.

20. Kubota K, Hidaka H, Nakazawa T, Okuwaki Y, Yamane K, Inoue T (2018) Prospective, randomized, controlled study of the efficacy of transcatheter arterial chemoembolization with miriplatin for hepatocellular carcinoma.

Hepatol Res 48:E98-E106.

21. Fiorentini G, Aliberti C, Benea G, Montagnani F, Mambrini A, Ballardini PL et al (2008) TACE of liver metastases from colorectal cancer adopting irinotecan-eluting beads: beneficial effect of palliative intra-arterial lidocaine and post-procedure supportive therapy on the control of side effects. Hepatogastroenterology 55:2077-2082.

22. Malagari K1, Pomoni M, Spyridopoulos TN, Moschouris H, Kelekis A, Dourakis S et al (2011) Safety profile of sequential transcatheter chemoembolization with DC Bead ${ }^{\mathrm{TM}}$ : results of 237 hepatocellular carcinoma (HCC) 
patients. Cardiovasc Intervent Radiol 34:774-785.

23. Narayanan G, Barbery K, Suthar R, Guerrero G, Arora G (2013) Transarterial chemoembolization using DEBIRI for treatment of hepatic metastases from colorectal cancer. Anticancer Res 33:2077-2083.

24. Tamura K, Aiba K, Saeki T, Nakanishi Y, Kamura T, Baba H (2015) Testing the effectiveness of antiemetic guidelines: results of a prospective registry by the CINV Study Group of Japan. Int J Clin Oncol 20:855-865.

25. Gan TJ, Diemunsch P, Habib AS, Kovac A, Kranke P, Meyer TA et al (2014) Consensus guidelines for the management of postoperative nausea and vomiting. Anesth Analg 118:85-113.

26. Elkrief L, Rautou PE, Sarin S, Valla D, Paradis V, Moreau R (2016) Diabetes mellitus in patients with cirrhosis: clinical implications and management. Liver Int 36:936-948. 
Table titles

Table 1. Patient's characteristics

$* P<0.05$

Table 2. Complete response rate and gastrointestinal symptoms

$* P<0.05, * * P<0.01$

Table 3. Severity of gastrointestinal symptoms

$* P<0.05, * * P<0.01$

Table 4. Incidence of post-embolization syndromes and adverse events

$* P<0.01$ 
Table 1. Patient's characteristics

\begin{tabular}{|c|c|c|c|}
\hline & $\begin{array}{l}\text { Control group } \\
\qquad(\mathrm{n}=101)\end{array}$ & $\begin{array}{l}\text { AE group } \\
(n=51)\end{array}$ & $P$-value \\
\hline Sex: male/female & $74 / 27$ & $37 / 14$ & 0.93 \\
\hline Age (median, range) & $69(33-88)$ & $69(42-88)$ & 0.47 \\
\hline \multicolumn{4}{|l|}{ Performance status (ECOG) } \\
\hline $0-1$ & 97 & 49 & \\
\hline $2-3$ & 4 & 2 & 0.99 \\
\hline Body mass index $\left(\mathrm{kg} / \mathrm{m}^{2}\right)$ & $23.8(14.9-33.7)$ & $24.5(16.1-39.9)$ & 0.88 \\
\hline Area of body surface $\left(\mathrm{m}^{2}\right)$ & $1.66(1.28-2.46)$ & $1.69(1.23-2.06)$ & 0.59 \\
\hline Liver dysfunction & 64 & 32 & 0.94 \\
\hline Serum creatinine & $0.74(0.27-7.3)$ & $0.76(0.45-2.74)$ & 0.18 \\
\hline \multicolumn{4}{|l|}{ TNM stage } \\
\hline \multicolumn{4}{|c|}{ (Liver Cancer Study Group of Japan) } \\
\hline I & 22 & 13 & \\
\hline II & 39 & 27 & \\
\hline III & 26 & 10 & \\
\hline IVA/IVB & 14 & 1 & $0.048^{*}$ \\
\hline \multicolumn{4}{|l|}{ Drinking history } \\
\hline None & 27 & 9 & \\
\hline Occasional drinking & 21 & 9 & \\
\hline Yes & 51 & 33 & 0.11 \\
\hline Pentazocine or fentanyl use & 50 & 33 & 0.09 \\
\hline Epirubicin dosage (mg) & $25(5.0-50.0)$ & $23(6.0-50.0)$ & 0.66 \\
\hline
\end{tabular}

$* P<0.05$ 
Table 2. Complete response rate and gastrointestinal symptoms

\begin{tabular}{|c|c|c|c|}
\hline & $\begin{array}{l}\text { Control group } \\
\qquad(\mathrm{n}=101)\end{array}$ & $\begin{array}{l}\text { AE group } \\
(n=51)\end{array}$ & $P$-value \\
\hline \multicolumn{4}{|l|}{ Complete response (n, \%) } \\
\hline Entire period & $54(54)$ & $39(76)$ & $9.0 \times 10^{-3 * *}$ \\
\hline Acute phase (day 1) & $60(59)$ & $40(78)$ & $0.03 *$ \\
\hline Delay phase (days $2-6$ ) & $78(77)$ & $46(90)$ & 0.07 \\
\hline \multicolumn{4}{|c|}{ Gastrointestinal symptom (n, \%) } \\
\hline \multicolumn{4}{|l|}{ Acute phase (day 1) } \\
\hline Nausea & $46(46)$ & $13(25)$ & $0.02 *$ \\
\hline Vomiting & $29(29)$ & $6(12)$ & $0.02 *$ \\
\hline Anorexia & $52(52)$ & $8(16)$ & $1.0 \times 10^{-5 * *}$ \\
\hline \multicolumn{4}{|l|}{ Delay phase (days 2-6) } \\
\hline Nausea & $32(32)$ & $11(22)$ & 0.25 \\
\hline Vomiting & $8(8)$ & $4(8)$ & 1.00 \\
\hline Anorexia & $59(59)$ & $13(25)$ & $1.0 \times 10^{-4 * *}$ \\
\hline
\end{tabular}

$* P<0.05, * * P<0.01$ 
Table 3. Severity of gastrointestinal symptoms

\begin{tabular}{|c|c|c|c|c|c|c|c|}
\hline & \multicolumn{3}{|c|}{ Control group $(n=101)$} & \multicolumn{3}{|c|}{ AE group $(n=51)$} & \multirow[b]{2}{*}{$P$-value } \\
\hline & Grade 1 & Grade 2 & Grade 3 & Grade 1 & Grade 2 & Grade 3 & \\
\hline \multicolumn{8}{|c|}{$\begin{array}{l}\text { Acute phase } \\
(\text { day 1) }(n, \%)\end{array}$} \\
\hline Nausea & $3(3)$ & $25(25)$ & $18(18)$ & $8(16)$ & $4(8)$ & $1(2)$ & $2.0 \times 10^{-3 * *}$ \\
\hline Vomiting & $26(26)$ & $3(3)$ & $0(0)$ & $5(10)$ & $1(2)$ & $0(0)$ & $0.02 *$ \\
\hline Anorexia & $1(1)$ & $32(32)$ & $21(21)$ & $2(4)$ & $5(10)$ & $1(2)$ & $2.6 \times 10^{-6 * *}$ \\
\hline
\end{tabular}

Delay phase

(days 2-6) (n, \%)

$\begin{array}{lccccccc}\text { Nausea } & 7(7) & 13(13) & 12(12) & 6(12) & 2(4) & 3(6) & 0.13 \\ \text { Vomiting } & 7(7) & 0(0) & 0(0) & 3(6) & 0(0) & 0(0) & 0.80 \\ \text { Anorexia } & 7(7) & 27(27) & 26(26) & 3(6) & 6(12) & 5(10) & 2.1 \times 10^{-4 * * *}\end{array}$

$* P<0.05, * * P<0.01$ 
Table 4. Incidence of post-embolization syndromes and adverse events

\begin{tabular}{|c|c|c|c|}
\hline & $\begin{array}{l}\text { Control group } \\
\qquad(\mathrm{n}=101)\end{array}$ & $\begin{array}{l}\text { AE group } \\
\qquad(\mathrm{n}=51)\end{array}$ & $P$-value \\
\hline \multicolumn{4}{|c|}{ Post-embolization syndrome (n, \%) } \\
\hline Acute phase (day 1) & & & \\
\hline Fever & $7(7)$ & $0(0)$ & $5.0 \times 10^{-3 * *}$ \\
\hline Abdominal pain & $50(50)$ & $8(16)$ & $4.0 \times 10^{-5 * *}$ \\
\hline \multicolumn{4}{|l|}{ Delay phase (days 2-6) } \\
\hline Fever & $82(82)$ & $23(45)$ & $5.0 \times 10^{-6 *}$ \\
\hline Abdominal pain & $70(70)$ & $19(37)$ & $1.0 \times 10^{-4 *}$ \\
\hline \multicolumn{4}{|l|}{ Adverse events (n, \%) } \\
\hline Acute phase (day 1 ) & & & \\
\hline Constipation & $7(7)$ & $1(2)$ & 0.27 \\
\hline Headache & $2(2)$ & $0(0)$ & 0.55 \\
\hline \multicolumn{4}{|l|}{ Delay phase (days 2-6) } \\
\hline Constipation & $22(22)$ & $25(49)$ & $1.0 \times 10^{-3 *}$ \\
\hline Headache & $14(14)$ & $5(10)$ & 0.61 \\
\hline
\end{tabular}

$* P<0.01$ 